Check for updates

London, UK

kathyoxtoby1@gmail.com

Cite this as: $B M J$ 2020;371:m4335 http://dx.doi.org/10.1136/bmj.m4335 Published: 10 December 2020
CHRISTMAS 2020: $M{ }^{*} A{ }^{*}{ }^{*} H$

\section{How we coped with covid-19-and silver linings}

Doctors and patients tell Kathy Oxtoby what has got them through the year, and the positives they have taken from 2020

\section{Kathy Oxtoby journalist}

Zoom meetings and audio books, camaraderie with colleagues and royal college work, running and long walks. These are just some of the ways doctors have been dealing with this difficult year.

To describe the year as challenging is, of course, a massive understatement. But along with the challenges presented by the pandemic have come positives, clinicians say, from a greater awareness of mental health and the importance of equality, to cleaner air and the closeness of family.

\section{Appreciation of the NHS brought me to tears}

Lade Smith, consultant psychiatrist, visiting senior lecturer, and clinical director, forensic services, Maudsley Hospital, London, and clinical director, National Collaborating Centre, Royal College of Psychiatrists

What's saved me has been audio books-after being at a computer reading all day I feel I can't pick up another book-and late evening walks.

I'm having more meetings with colleagues, where we pass on information but also check in with each other to ask how we're feeling.

IT turned into superheroes, putting over 800 staff to remote access in five days. And colleagues are covering for others who are unable to come to work because they are shielding or in a potentially high risk group. I've been really impressed with how readily they've been doing this.

And it's been heartening that people, some of whom I haven't heard from for a long time, are remembering me, remembering I'm a health worker, and asking,

“Are you ok, are you safe?"

The first time that people clapped for the NHS I was a bit cynical. By the third time, when things had got so overwhelming, hearing everyone clapping I found myself in tears to hear that ring of appreciation for the NHS.

\section{I have re-evaluated what's important in my life}

lan Higginson, consultant in emergency medicine, University Hospitals Plymouth NHS Trust, and vice president, Royal College of Emergency Medicine

Having the family together during lockdown was reassuring-it felt like we were "hunkering down" for whatever was to come. I also have a friendship network composed of people with a strong sense of community and a good sense of humour.
Being part of an incredible emergency department team has helped. We stayed positive, and it felt good to continue to provide care for patients during this time of great need. And my royal college work has enabled me to feel I've made a contribution both to disseminating information relating to covid and emergency medicine's response to it.

The pandemic has prompted me to re-evaluate what's important in life and get my work-life balance sorted. I'm a drummer, and playing live is hard to do during a pandemic, but I've learnt more about mixing and music production.

Video conferencing has enabled those of us working in emergency medicine to connect with each other across national and international borders, sharing our concerns and successes. I hope we'll continue to share our incredible experiences across the world.

\section{I've been out exploring in the fresh air}

David Turner, GP partner, Chorley Wood Health Centre, Hertfordshire

Our team really pulled together and knuckled down to convert the practice mostly to phone appointments, then later, to start ramping up face-to-face appointments.

As well as maintaining the surgery routine to keep things as normal as possible, I've been cycling, walking, and exploring local areas I didn't know existed.

There's been less traffic on the roads so it's been nice to be out in the fresh air, which is cleaner. With less traffic my journey to work has gone down from an hour and a half to 15 minutes, which has made a huge difference to my day.

During the first few weeks [of the pandemic] things were quieter, and I had time to catch up on routine stuff like updating records and QOF [Quality and Outcomes Framework]. And we were only dealing with patients with serious problems-so for a while there were no "worried well."

\section{Clinical researchers are more collaborative now}

Sarah Markham, visiting researcher, Institute of Psychiatry, Psychology and Neuroscience, King's 


\section{College London, and member of The BMJ patient panel}

Ironically, what's helped me is that I'm a mental health patient. This has given me so many opportunities through life to build up resilience, to learn to take things in my stride, as well as experience of facing uncertainty, negative outcomes, and risk.

I've been detained under the Mental Health Act so have had previous experience of a kind of lockdown-so nothing that has been implemented has bothered me.

As I'm an academic researcher, covid has brought me lots of interesting work. I'm currently working on a systematic review of mental health research that's been initiated in response to the pandemic.

Historically, clinical research teams can be competitive with each other, whereas now it's in everyone's best interest to collaborate to better understand the virus, which is a positive change.

\section{"Pizza Fridays" have kept me going}

\section{Richard Fieldhouse, chair of National Association of Sessional GPs (NASGP) and locum GP in Chichester, West Sussex}

At the beginning of the pandemic across the country most locum work was cancelled, so doing [fewer] sessions helped me focus on my work with the National Association of Sessional GPs (NASGP).

What's been getting me through is being able to make a difference to the lives of GP locums. My wife-also a locum-and I both help run NASGP, and we've been spending time making the organisation's locum IT software LocumDeck more powerful and much simpler to use.

We've also launched a network of GP locum chambers, which are managed local collectives of self-employed locums supporting local practices.

My pizza oven has kept me going. I bought a portable pizza oven a few years back, and I've been having pizza Fridays.

As much as I miss my sons visiting, I'm no longer exposed to their cats' allergens. So now I can go running for 10 miles without any puff of an inhaler for the first time in decades.

\section{Running is a form of meditation and relaxation}

Ceinwen Giles, director of partnerships and evaluation, Shine Cancer Support, a cancer support charity for young people

Awful as things have been this year, what has got me through is the team I work with. A small team of five, we have all had a cancer diagnosis, are all in the same situation, and stay in touch with each other personally as well as professionally.

Running has helped a lot. I have an immune deficiency, and in the darkest days of lockdown, when I was having to shield, I went running every day by myself. For me it's a form of meditation and relaxation.

It's been nice to spend more time with my husband and daughter, even though there were times when we drove each other crazy.

We used to run three-day retreats on coping with a cancer diagnosis but have had to redesign these programmes to be delivered online. Even if things go back to normal we'll keep some of our online programmes because we can reach people in different parts of the country more easily.
There's been a lot of camaraderie within our online patient community, and it's helped to make sure people don't feel alone and isolated.

\section{My NHS family gave me a sense of purpose}

Farah Bhatti, consultant cardiothoracic surgeon and council member of Royal College of Surgeons of England

While so many people were furloughed, shielding, and feeling isolated, being able to continue working with my NHS family gave me a sense of purpose through the crisis.

It's also been great to share guidance and help to define best practice and with issues concerning healthcare staff such as PPE availability and testing.

I also have an extremely supportive husband, who is with me through thick and thin.

This year has shone a light on the terrible things happening in the world, such as the increased risk of covid in ethnic minority communities and the killing of George Floyd, renewing interest in Black Lives Matter. We mustn't stop trying to create a more equitable society.

I'm very involved in equality, diversity, and inclusion-it's what drives me. I feel honoured to have been invited onto an independent panel to look at diversity in the leadership of the Royal College of Surgeons of England. That's a good thing to come out of this difficult year.

\section{“Online connections are like having an extended family}

\section{Liz Bragg, associate specialist paediatrician, Cardiff and Vale University Health Board}

Zoom meetings with colleagues stopped me quietly going mad with my own company. I worked from home for six weeks-I was shielded because of health problems - so seeing people by Zoom made a massive difference.

Group chats on Facebook with like-minded people is like having an extended family. We take it in turns to support each other, share how awful things feel, and get group reassurance.

I was impressed with the way our IT department organised laptops for staff to work from home. I've been asking for years if I can access emails from home-during the pandemic this happened within days.

It's good that lots of people are suddenly thinking about mental health. There's a greater awareness that everybody needs to watch everybody's backs to make sure they're coping.

I liked the lack of emissions-that we were letting the planet breathe again. And having connections with people will continue to get me through. Staying connected is what makes us human. 